João Pessoa, v. 3, n. 3, p. 68-83, set./dez. 2015. ISSN 2318-1001

DOI: 10.18405/recfin 20150305

Disponível em: http://periodicos.ufpb.br/ojs2/index.php/recfin

\title{
EXPERIÊNCIAS INTERNACIONAIS E DESAFIOS DOS GOVERNOS DOS PAÍSES NA TRANSIÇÃO DA CONTABILIDADE PÚBLICA PARA O REGIME DE COMPETÊNCIA ${ }^{1 *}$
}

\author{
INTERNATIONAL EXPERIENCES AND CHALLENGES OF THE \\ GOVERNMENTS OF COUNTRIES IN THE TRANSITION OF PUBLIC \\ ACCOUNTING TO ACCRUAL BASIS
}

\author{
Brenno Carvalho Botelho ${ }^{2}$ \\ Graduado em Ciências Contábeis pela UnB \\ brenno0507@gmail.com
}

\begin{abstract}
Diana Vaz de Lima
Doutora em Ciências Contábeis pelo Programa Multiinstitucional e Inter-regional UnB/UFPB/UFRN Professora do Programa de Pós-Graduação em Ciências Contábeis da UnB

diana.lima@uol.com.br
\end{abstract}

\section{RESUMO}

O presente estudo tem como objetivo apresentar experiências internacionais e os desafios enfrentados pelos Governos dos países na transição da contabilidade pública para o regime contábil de competência. Sua contribuição está na atualização da literatura no que tange ao posicionamento dos governos de economias mundiais quanto à adoção do accrual basis em sua contabilidade e, principalmente, por evidenciar os principais procedimentos observados durante o processo de transição. Para tratar a questão da pesquisa, são discutidos os procedimentos recomendados pelo Study 14, desenvolvido pela International Federation of Accountants (IFAC), e pelo Modelo de Requerimentos Básicos (BRM, em inglês), proposto por Ouda (2008), e analisadas as experiências monitoradas pela IFAC nos Governos da Malásia, Malta e Suíça; as experiências relatadas na literatura (Romênia, Nova Zelândia e Austrália); e a experiência vivenciada pelo Governo brasileiro, por meio de informações coletadas no sítio da Secretaria do Tesouro Nacional do Brasil e em artigos acadêmicos. Os resultados mostram que os Governos da Suiça, Austrália e Nova Zelândia já adotam o regime de competência integral e seguiram todos os procedimentos recomendados pelo Study 14 e pelo BRM. No caso da Romênia, apesar de utilizar o regime de competência integral, não adotou a maior parte dos procedimentos recomendados, o que pode explicar o fato de as informações geradas em sua contabilidade não serem utilizadas nem pelos gestores e nem pelas autoridades governamentais. No caso dos Governos da Malásia e de Malta, definiram o ano de 2019 como data limite para a transição para o regime de competência integral. Quanto ao Brasil, adota-se o regime de competência modifi-

\footnotetext{
${ }^{1}$ Recebido em 03/09/2015. Revisado por pares em 28/09/2015. 2 ${ }^{\underline{a}}$ versão recebida em 29/11/2015. Recomendado à publicação em 05/12/2015 por Orleans Silva Martins (Editor Geral). Publicado em 10/12/2015. Organização responsável: UFPB.

* Artigo apresentado no XI Congresso USP de Iniciação Científica em Contabilidade, São Paulo/SP, entre os dias 29 e 31 de julho de 2015.

2 Endereço: Universidade de Brasília, Campus Darci Ribeiro, FACE, Salas B1-02, Asa Norte, CEP 70.910-900, Brasília/DF. DOI: http://dx.doi.org/10.18405/recfin20150305
} 
cado, sem previsão para adoção integral do regime de competência. Com relação aos desafios observados no processo de transição, destaca-se, nessa ordem, carência de pessoal treinado, exigências tecnológicas, falta de comprometimento da alta administração, custo da conversão e impacto esperado sobre a situação patrimonial e financeira divulgada.

Palavras-Chaves: Regime de Competência; Processo de Convergência; Contabilidade Pública; Experiências Internacionais.

\section{ABSTRACT}

The present study aimed at presenting international experiences and challenges faced by the governments of countries in the transition from public accounting to the accrual basis of accounting. His contribution lies in the literature update regarding the positioning of economies of governments on the adoption of the accrual basis in its accounting, and especially by highlighting the main procedures observed during the transition process. To address the issue of research, we discuss the procedures recommended by the Study 14, developed by the International Federation of Accountants (IFAC), and the Basic Requirements Model (BRM, in English), proposed by the researcher Ouda (2008), and analyzed IFAC experiences monitored by the governments of Malaysia, Malta and Switzerland; the experiences reported in the literature (Romania, New Zealand and Australia), collected from academic publications; and the experience lived by the Brazilian government, through information collected on the website of the National Treasury of Brazil and scholarly articles published on the subject. The results show that the governments of Switzerland, Australia and New Zealand have adopted the full accrual basis and followed all the procedures recommended by the Study 14 and the BRM. In the case of Romania, despite using the full accrual basis did not adopt most of the recommended procedures, which may explain the fact that the information generated in its accounts not being used or by managers and not by government authorities. In the case of the Governments of Malaysia and Malta have set the year 2019 as the deadline for the transition to full accrual basis. As for Brazil, it adopts the modified accrual basis, with no provision for full adoption of the accrual basis. Regarding the challenges observed in the transition process, stands out, in that order, lack of trained personnel, technological requirements, lack of senior management commitment, cost of conversion and the expected impact on the financial situation disclosed.

Keywords: Accrual Basis; Process of Convergence; Public Accounting; International Experiences.

\section{INTRODUÇÃO}

O regime de competência, também conhecido como accrual basis, é um método contábil na qual as transações e os eventos econômicos são registrados e divulgados por ocasião de sua ocorrência, independentemente do momento do seu recebimento ou pagamento. Segundo relatório da empresa de consultoria Ernst \& Young (2012), o processo de harmonização internacional das normas contábeis no âmbito dos Governos dos países perpassa a necessidade da implantação integral do regime contábil de competência para o registro dos atos e fatos relevantes na perspectiva dos stakeholders.

De acordo com Chan (2010), embora existam produções científicas que não apoiam a utilização do regime de competência no âmbito do Setor Público, o fato é que as informações geradas a partir do uso correto do regime de competência, tanto na contabilidade pública quanto na societária, refletem de forma mais adequada a realidade das transações.

Segundo informações disponibilizadas no relatório da empresa de consultoria PricewaterhouseCoopers (PWC, 2013), existe uma necessidade real de que os relatórios emitidos pelo Setor Público demonstrem mais solidez e transparência, e que as demonstrações contábeis dos Governos passem a refletir integralmente o impacto econômico das decisões políticas, o que só poderia ser alcançado plenamente com a adoção do regime de competência. 
No Brasil, o processo de convergência aos padrões contábeis internacionais no âmbito do Setor Público tem sido conduzido pelo Conselho Federal de Contabilidade (CFC) e operacionalizado pela Secretaria do Tesouro Nacional (STN). Um dos aspectos que vem merecendo maior discussão encontra-se justamente relacionado à adoção integral do regime contábil de competência, em razão de, até recentemente, à prática de a contabilidade pública brasileira ser adepta ao regime de execução orçamentária e financeira, no qual as receitas são reconhecidas apenas no momento da arrecadação e as despesas no momento do empenho.

De acordo com o CFC (2007), as normas internacionais dispõem sobre uma contabilidade patrimonial integral, o que requer o registro de todos os itens de bens, direitos, obrigações e patrimônio líquido da entidade considerada, e estabelecem o regime de competência para o reconhecimento de receitas e despesas. Sem a adoção desse regime, diversos ativos e passivos podem não ser reconhecidos, e o objetivo de evidenciar a situação financeira e os resultados do exercício fica fortemente prejudicado.

Pilcher (2009, apud Borges, 2010), entende que a implantação do regime contábil de competência é deveras complexa, visto que envolve uma série de questões que não se resume a aspectos puramente contábeis, com consequências que se estendem à questão política. Segundo os pesquisadores, um provável risco da transição para o regime de competência é a frequente mudança em padrões contábeis para atender às especificidades de cada governo local, o que poderia levar à manipulação de resultados com a finalidade de atingir metas fiscais.

Borges (2010) também comenta que outra questão que poderia justificar a dificuldade da adoção do accrual basis na contabilidade pública brasileira seria a falta de informações sobre o fato gerador, por exemplo, das receitas tributárias. Entretanto, com o advento da Lei de Responsabilidade Fiscal e do Sistema Público de Escrituração Digital (SPED), o autor considera que é possível que o ente público, no momento da emissão da nota fiscal, reconheça a receita e o direito do valor a receber, uma vez que seria factível sua mensuração e individualização.

Ainda que a adoção do regime contábil de competência represente um grande desafio por parte dos Governos, o fato é que ele tem sido paulatinamente adotado tanto nos países que seguem o modelo anglo-saxão de contabilidade como nos países que seguem o modelo de contabilidade continental (NIYAMA, 2013), a exemplo da Espanha, Nova Zelândia, Suécia, Estados Unidos, Reino Unido, Canadá, Finlândia, França e Austrália (HERBEST, 2010).

Diante do exposto, considerando que a adoção do regime contábil de competência é um ponto crucial para o processo de convergência aos padrões contábeis internacionais do Setor Público, e o fato de que os registros contábeis devem refletir a essência das transações e não meramente a sua forma legal, o presente estudo traz a seguinte questão de pesquisa: quais requisitos têm sido observados e quais desafios têm sido enfrentados pelos Governos dos países na transição da contabilidade pública para o regime contábil de competência? Portanto, o presente estudo tem como objetivo apresentar experiências internacionais e os desafios enfrentados pelos Governos dos países na transição da contabilidade pública para o regime contábil de competência.

Para tratar a questão da pesquisa, são discutidos os procedimentos recomendados pelo Study 14, desenvolvido pela International Federation of Accountants (IFAC), e pelo Modelo de Requerimentos Básicos (BRM, em inglês), proposto pelo pesquisador Ouda (2008), e analisadas as experiências monitoradas pela IFAC nos Governos da Malásia, Malta e Suíça; as experiências relatadas na literatura (Romênia, Nova Zelândia e Austrália), coletadas de publicações acadêmicas; e a experiência vivenciada pelo Governo brasileiro, por meio de informações coletadas no sítio da Secretaria do Tesouro Nacional do Brasil e de artigos acadêmicos publicados sobre o assunto. Destaca-se a importância deste estudo pela atualização da literatura, quanto ao posicionamento dos governos de economias mundiais quanto à adoção do accrual basis em sua contabilidade e, principalmente, por evidenciar os principais procedimentos observados durante o processo de transição. 
Além desta introdução, o presente estudo possui mais quatro seções. Na seção 2, são apresentados os aspectos conceituais e normativos dos regimes contábeis governamentais e os procedimentos recomendados para a adoção do regime de competência no Setor Público. O proceder metodológico adotado para a realização da pesquisa é descrito na Seção 3. Na Seção 4, são apresentadas as experiências nacionais e internacionais no processo de transição, bem como os desafios enfrentados pelos Governos dos Países analisados. As considerações finais são apresentadas na Seção 5, seguidas das referências utilizadas.

\section{REFERENCIAL TEÓRICO E NORMATIVO}

\subsection{Aspectos Conceituais e Normativos dos Regimes Contábeis Governamentais}

De acordo com Wilges (2006), os regimes contábeis representam fórmulas para apuração periódica dos resultados financeiros, patrimonial ou econômico do exercício. Sousa et al. (2013) reconhecem a existência do regime contábil de caixa e do regime contábil de competência, e comentam que há duas variações decorrentes desses regimes: o regime de caixa modificado e o regime de competência modificado. Esses regimes e suas variações também podem ser observados em publicações como reports e exposure drafts, editados pela International Federation of Accountants (IFAC).

Na visão de Sousa et al. (2013), no regime de caixa o registro das receitas só ocorre quando há o efetivo recebimento de valores, e as despesas não são reconhecidas até que sejam efetivamente pagas. Para Chan (2010), o regime de caixa, por definição, exclui o reconhecimento de alguns ativos e passivos não monetários, como os subsídios a receber e os empréstimos a pagar.

Com relação ao regime de competência, Cruvinel e Lima (2011) esclarecem que representa o método que reflete de forma mais aplicável o desempenho econômico no resultado do exercício, segundo o qual as receitas e as despesas são reconhecidas independentemente da entrada ou da saída de recursos financeiros na entidade. A Resolução CFC nº 1.282/10, que atualiza e consolida os dispositivos da Resolução CFC no 750/93, que dispõe sobre os Princípios de Contabilidade, traz em seu artigo $9^{\circ}$ a definição do Princípio de Competência:

O princípio da Competência determina que os efeitos das transações e outros eventos sejam reconhecidos nos períodos a que se referem, independentemente do recebimento ou pagamento e pressupõe a simultaneidade da confrontação de receitas e despesas correlatas.

Assim, enquanto no regime de caixa as receitas e despesas são registradas contabilmente quando da efetiva movimentação financeira, no regime de competência todas as operações são registradas no período a que se relacionam (FEE, 2007).

Com relação ao regime de caixa modificado, Das (2008, apud Dutra e Jesus, 2012), esclarece que o mesmo ocorre mediante o reconhecimento das transações sob o regime de caixa ao longo do exercício, mantendo-se, contudo, os livros contábeis abertos após o seu término para o registro de pagamentos e recebimentos referentes ao exercício anterior. No caso do regime de competência modificado, há o registro de todos os ativos e passivos, porém, com limitações na mensuração, além de as transferências e subsídios governamentais permanecerem sendo registrados com base no regime de caixa (MONTESINOS; VELA, 2000, apud DUTRA; JESUS, 2012).

Para Diamond (2012), o mérito da utilização do accrual basis é gerar, entre outros, maior transparência das operações e da gestão de direitos e obrigações, além de melhorar a qualidade da informação para decisão, uma vez que boas informações de custos levam a estimativas mais confiáveis e a melhor alocação dos recursos públicos. Saleh e Pendlebury (2006, apud Borges, 2010) entendem que a adoção do regime de competência torna mais precisa a avaliação dos indicadores de desempenho pelos órgãos de controle.

Ao apresentar a estrutura conceitual para uso geral nos relatórios financeiros das entidades do Setor Público, a IFAC comenta que os relatórios financeiros contemplados nas International Public 
Sector Accounting Standards (IPSAS) e nas estatísticas financeiras governamentais (GFS, em inglês) têm em comum o fato de suas estruturas conceituais levarem em consideração informações financeiras geradas a partir do regime contábil de competência - item 22 - (IFAC, 2014a).

De acordo com o disposto na Norma Internacional de Contabilidade Aplicada ao Setor Público (IPSAS 1), que trata da apresentação das demonstrações contábeis, o regime de competência é o regime contábil segundo o qual as transações e outros eventos são reconhecidos quando ocorrem (não necessariamente quando o caixa ou seus equivalentes são recebidos ou pagos), devendo as transações e eventos ser registrados contabilmente e reconhecidos nas demonstrações contábeis referentes aos respectivos períodos - item 7 - (IFAC, 2014b).

Cruvinel e Lima (2011) esclarecem que a ocorrência do fato gerador está vinculada à origem do ato ou fato administrativo, momento em que, no regime de competência, é feito o registro contábil mediante adequado processo de mensuração e reconhecimento. Na visão de Guthrie (1998), a utilização do regime de competência evidencia completamente os custos das atividades governamentais devido ao reconhecimento de itens como a depreciação e o goodwill. Borges (2010) comenta que informações incompletas, não confiáveis e inoportunas sobre o desempenho de um Governo dificultam o cumprimento de suas responsabilidades, além de representar um obstáculo à arrecadação governamental, o que levaria à redução da capacidade de geração de caixa para cumprimento das obrigações.

No entendimento da Fédération des Experts Comptables Européens (FEE, 2007), o accrual accounting facilita o planejamento, o gerenciamento e a tomada de decisão, fornecendo o escopo necessário a uma gestão financeira mais efetiva, além de permitir comparações sobre o desempenho financeiro de departamentos e agências de um Governo ou ainda entre governos. Para Herbest (2010), embora a falta de vontade política gere grandes dificuldades na implantação do regime de competência, existe uma série de incentivos para a sua adoção na contabilidade pública internacional, visto que representa um aumento da eficiência da alocação dos recursos por parte do Governo. Segundo o autor, órgãos de grande representatividade como a IFAC, o Fundo Monetário Internacional (FMI) e a União Europeia apoiam a adoção integral do regime contábil de competência.

A tendência mundial para adoção do regime de competência integral pelos Governos dos países é apresentada em pesquisa realizada pela empresa de consultoria PricewaterhouseCoopers (PWC, 2013), comparando o mapa global de adoção no ano de 2013 e sua projeção em cinco anos. De acordo com a pesquisa, enquanto no ano de 2013 apenas 26 Governos de países adotava o regime de competência, a expectativa é que, em 2018, 63 países estejam nesta condição, representando um aumento de mais de $140 \%$. Mangualde (2013) alerta que o posicionamento de grandes economias mundiais nesse sentido evidencia a importância da adoção do regime de competência no âmbito dos Governos dos países para alcance de objetivos propostos pela nova Administração Pública, que tem foco no resultado e na busca da eficiência administrativa.

\subsection{Procedimentos Recomendados para Adoção do Regime de Competência no Setor Público}

Estudos têm sido desenvolvidos visando apresentar procedimentos que permitam que os Governos dos países promovam a transição dos seus regimes contábeis para o regime de competência, a exemplo do Study 14 desenvolvido pela IFAC, e do Modelo de Requerimentos Básicos (BRM, em inglês) proposto pelo pesquisador Ouda.

Com relação ao Study 14, a expectativa da IFAC é dar o suporte necessário aos países que já adotaram, estão em processo de transição ou pretendem efetuar a transição para o accrual basis, auxiliando economias mundiais durante o processo de convergência aos padrões contábeis internacionais. Embora seja bastante variável de acordo com a jurisdição de cada entidade, esse estudo pretende ser útil para localizar sua posição no processo de transição e onde os esforços precisam se concentrar para completar a transição. 
O Study 14 também relaciona os procedimentos que devem ser adotados para a adoção integral do regime contábil de competência, salientando, entre eles, a demanda de tempo, investimento e interesse governamental. Na visão do estudo, a utilização do regime de competência na contabilidade pública representa uma série de avanços quanto à evidenciação da posição financeira, do desempenho financeiro e dos fluxos de caixa das entidades, entendendo que as informações contábeis geradas pelo accrual basis são úteis tanto para a prestação de contas quanto para a tomada de decisão (IFAC, 2011).

A IFAC (2011) comenta, mais detalhadamente, que a adoção do accrual basis permite mostrar como a entidade financia suas atividades e compreender sua necessidade de caixa, possibilitando que os usuários da informação contábil possam analisar a capacidade contínua da entidade de financiar suas atividades através da análise de seus passivos.

De acordo com o Study 14, entre os procedimentos necessários para adoção do accrual basis, a entidade deve possuir classificações específicas que identifiquem as receitas e despesas de cada entidade e de cada programa, sua área de atividade ou ainda algum componente exigido por norma; e a depreciação, a amortização e a imparidade dos seus elementos patrimoniais (IFAC, 2011). Para que o processo de transição para o regime de competência se dê de maneira mais simples e rápida, o Study 14 da IFAC relaciona os requisitos que devem ser observados, como os destacados a seguir:

a. Comprometimento Político e de Unidades Centrais: é necessário o comprometimento político de todos os envolvidos no processo inclusive da oposição política, uma vez que o processo é longo e pode ultrapassar um ou mais mandatos. Falhar nesse quesito pode gerar o desperdício de recursos financeiros;

b. Adequação de Recursos Humanos e Financeiros: são requeridos tipos específicos de habilidades para a condução do processo e o governo deve dotar de financiamento adicional para a contratação de mais servidores e especialistas e para a instalação de sistemas de informações financeiras;

c. Efetiva Estrutura de Gestão do Projeto: é necessária uma estrutura conceitual documentada, um plano formal de implantação, clara atribuição de responsabilidades, marcos do projeto e monitoramento do desempenho, definição de autoridades decisórias, expectativa de custos adicionais, entre outros;

d. Adequação dos Sistemas Tecnológicos e Informacionais: é preciso estabelecer ligações entre todos os sistemas existentes que influenciem a divulgação das informações financeiras;

e. Uso da Legislação: o uso da legislação permite dar autoridade formal para os procedimentos e demonstra o compromisso do governo com a mudança, além de ter maior alcance do que normativos infralegais.

Sobre o modelo BRM, proposto por Ouda (2008), para ser melhor entendido o processo de transição deve considerar fatores explanatórios, que explicam como e porque a transição funcionou bem em alguns países e em outros não, identificando quais fatores ou variáveis são fundamentais para a mudança. Para o modelo, também devem ser monitorados os fatores de implantação, que identificam as ações que devem ser postas em prática para criar as condições apropriadas para a introdução do novo regime, a partir dos seguintes elementos: estímulo, reforma do processo decisório, estrutura para implantação, resultados e consequências:

i. Estímulo: deve haver algum estímulo para a transição, como uma crise econômica, escândalos de corrupção, pressão de organismos internacionais, entre outros;

ii. Reforma do Processo Decisório: é necessário que haja vontade política para a transição;

iii. Estrutura para Implantação: são necessárias mudanças culturais, suporte burocrático, suporte acadêmico e profissional, boa vontade, consultoria e coordenação, orçamento dos 
custos de transição, superação de problemas contábeis específicos (identificação e valoração de ativos fixos, por exemplo), integração entre contabilidade e orçamento, capacidade dos sistemas de tecnologia da informação (TI) e suporte financeiro internacional;

iv. Resultados: os resultados da implantação do novo regime e da reforma governamental devem ser conhecidos, o que significa dizer que os resultados da implantação devem ser divulgados.

v. Consequências: também deve ser demonstrado o impacto da reforma na melhoria da qualidade das informações geradas (melhoria na gestão de ativos e passivos, melhoria na mensuração e gestão de custos, informação total de custos de programas e atividades governamentais, entre outros).

Vale destacar a existência de outros modelos, como o processo de reforma da gestão financeira proposto por Lüder (2002), cujas recomendações também podem ser observadas no BRM de Ouda (2008) e no Study 14 da IFAC (2011), e as precondições para o sucesso da transição para o regime de competência no Setor Público propostas por Hepworth (2003).

\section{METODOLOGIA}

Quanto aos objetivos, a presente pesquisa é exploratória, tendo em vista que, segundo Raupp e Beuren (2006), caracteriza-se por proporcionar uma visão geral sobre determinado fato. No presente estudo, busca-se apresentar experiências internacionais e os desafios enfrentados pelos Governos dos países na transição da contabilidade pública para o regime contábil de competência. Quanto à abordagem do problema, trata-se de pesquisa qualitativa, tendo em vista que há o aprofundamento do objeto que está sendo estudado por meio de análises sem o emprego de um instrumento estatístico como base. Em relação aos procedimentos, a pesquisa será desenvolvida por meio de análise bibliográfica e documental das experiências internacionais no processo de transição para o regime contábil de competência, de publicações acadêmicas e relatórios internacionais de entes governamentais e não governamentais.

Serão discutidos os procedimentos recomendados pelo Study 14, desenvolvido pela International Federation of Accountants (IFAC) e pelo Modelo de Requerimentos Básicos (BRM, em inglês), proposto por Ouda (2008), quais sejam: comprometimento político, adequação dos recursos humanos e financeiros, efetiva estrutura de gestão do projeto, adequação dos sistemas tecnológicos, uso da legislação, estímulo, estrutura para implantação, resultados e consequências.

Foram selecionadas para análise três experiências de Governos de países monitorados pela IFAC que, no momento da realização desta pesquisa, no período de julho a novembro de 2014, se encontravam em processo de transição para o regime de competência: Malásia, Malta e Suíça. Essa escolha também se deu em razão de o CFC, na qualidade de órgão regulador das práticas contábeis no Brasil, instituir grupos de estudo com a finalidade de estudar e propor normas brasileiras de contabilidade aplicadas ao Setor Público alinhadas com essas normas internacionais publicadas pela IFAC (CFC, 2007).

Quanto às experiências relatadas na literatura, foram selecionados os Governos da Austrália e da Nova Zelândia, que, segundo pesquisa apresentada por Herbest (2010), apresentavam grande quantidade de estudos, o que possibilitaria efetuar a análise dos itens objeto do estudo. Quanto à análise da experiência do Governo da Romênia, a escolha se fundamentou na pesquisa de Pitulice (2014), que demonstrou que mesmo com a adoção do regime de competência os gestores públicos deste país não utilizavam as informações contábeis no processo decisório, contrariando a expectativa gerada no âmbito do Setor Público brasileiro (CFC, 2007). 
Finalmente, o relato da experiência brasileira tem como propósito verificar em que medida o Governo brasileiro vem conseguindo implantar o conjunto de orientações estratégicas estabelecidas pelo CFC no sentido de identificar, estimular, adotar e manter boas práticas de governança e de contabilidade, consubstanciadas nas normas internacionais de contabilidade aplicadas ao setor público e nas experiências acumuladas (CFC, 2007).

As experiências selecionadas foram analisadas com base nos procedimentos recomendados pelo Study 14 da IFAC e nos requerimentos básicos propostos por Ouda (2008). Para cada procedimento recomendado, foi verificado se o processo de convergência atende (S), atende parcialmente $(\mathrm{P})$ ou não atende $(\mathrm{N})$, a partir dos relatórios divulgados pela IFAC e dos achados relatados na literatura objeto de análise. Foram classificados por " $\mathrm{S}$ " os procedimentos que, segundo os relatos observados, foram adotados conforme recomendado pelo Study 14 e/ou por Ouda (2008). Para os procedimentos que foram adotados de forma parcial, ou seja, não foram seguidas todas as recomendações do Study 14 ou de Ouda, atribuiu-se a classificação “ $\mathrm{P}$ ". Classificou-se por "N" os procedimentos recomendados que, segundo os relatos analisados, não foram adotados pelo país durante o processo de convergência.

A pesquisa foi estruturada de acordo com a origem das informações analisadas para o desenvolvimento do estudo. No tópico 4.1 são evidenciadas as experiências analisadas segundo informações da IFAC. As experiências descritas no tópico 4.2 derivam da análise de publicações acadêmicas internacionais. A experiência brasileira, relatada no tópico 4.3, resulta da análise das informações disponíveis no sítio da STN e em publicações acadêmicas nacionais. Ressalta-se como limitação do método a utilização de fontes secundárias para a coleta de dados.

\section{EXPERIÊNCIAS INTERNACIONAIS E DESAFIOS DOS GOVERNOS DOS PAÍSES NA TRANSIÇÃO PARA O REGIME CONTÁBIL DE COMPETÊNCIA}

\subsection{Experiências Internacionais Monitoradas pela IFAC}

Com relação à experiência do Governo da Malásia, a expectativa é que a transição para o regime de competência se dê a partir do exercício financeiro de 2015, sendo identificados quatro aspectos que merecem destaque em seu processo de transição: (i) a criação do Government Accounting Standards Advisory Committee (GASAC), que tem a função de revisar e rascunhar normas contábeis baseadas nas Malaysia Public Sector Accounting Standards (MPSAS), normas locais desenvolvidas com bases nas IPSAS; (ii) a identificação e proposição, pelo GASAC, de emendas a leis e regulamentações; (iii) a necessária adaptação dos sistemas de tecnologia da informação; e (iv) a necessidade de uma ampla mudança na gestão e desenvolvimento de programas de capacitação e treinamento. Foi estimado um quantitativo de 65 a 70 mil pessoas que necessitam de treinamento, sendo que a maioria tem conhecimento contábil mínimo ou nenhum. De acordo com o plano de transição do Governo da Malásia, as receitas de impostos passarão a ser reconhecidas com base no regime de competência em etapas, sendo que até o ano de 2019 as receitas serão reconhecidas com base no accrual basis, com exceção de algumas receitas, por exemplo, multas de trânsito.

Na experiência do Governo de Malta, segundo relatório datado de Janeiro de 2014, disponível no sítio da IFAC, o processo de transição foi inicialmente impulsionado a partir do reconhecimento pela Comissão Europeia de que as IPSAS representam uma referência de grande importância para a harmonização da contabilidade do Setor Público. O manifesto apoio à adoção das normas internacionais sinalizado pelo ministro e pelo secretário permanente do ministério de finanças do País também foi considerado de fundamental importância para prováveis futuras mudanças legislativas que serão necessárias. Com relação à adoção do regime de competência, no Governo de Malta terá seu início em 2016 pelo ministério de finanças, e a expectativa é que também até o ano de 2019 todos os departamentos e ministérios gerem informações a partir do regime de competência. 
A experiência do Governo da Suíça mostra que a principal motivação para a adoção do regime de competência é o aumento da transparência de custos no nível dos ministérios e unidades administrativas. Contudo, a transição para o accrual basis representa um grande desafio para as unidades administrativas em virtude da necessidade de aprimorar o conhecimento contábil. Além disso, faz-se necessária uma reorganização de tarefas e competências em conjunto com a realocação de trabalhos. Para o treinamento dos especialistas, devem ser utilizados cursos educacionais e um abrangente manual de contabilidade fornecido pela administração financeira federal. No Governo da Suíça foram implantados um novo sistema contábil e um novo sistema de tecnologia da informação, que integra a contabilidade de unidades administrativas em um sistema contábil central. Segundo Herbest (2010) os softwares utilizados na contabilidade do Governo Suíço são viáveis e contam com suporte dos órgãos reguladores.

Ainda que tenham sido inicialmente empreendidos esforços substanciais para o fortalecimento do conjunto interno de conhecimentos práticos para minimizar a utilização de aconselhamento externo, a administração financeira federal do Governo Suíço recebeu assistência de empresas de consultoria para reduzir os riscos da implantação das novas práticas. Outra questão levada à discussão foi a necessidade de capacitação de alguns stakeholders, principalmente os membros do parlamento, para a perfeita compreensão das informações geradas pela contabilidade mediante a utilização do regime de competência. Segundo Herbest (2010), entre as maiores dificuldades encontradas pelo Governo da Suíça estão a grande quantidade de normativos e a elaboração do orçamento com base no regime de caixa, o que vêm sendo solucionado com o desenvolvimento de novas práticas contábeis.

\subsection{Experiências Internacionais Relatadas na Literatura}

Na experiência do Governo da Nova Zelândia, Champoux (2006) afirma que a transição para o regime de competência se iniciou juntamente com uma série de reformas econômicas, datadas da segunda metade da década de 1980, marcadas por uma série de privatizações. Com a finalidade de melhorar o desempenho financeiro e a accountability nas entidades governamentais restantes, o Governo decidiu adotar modernas práticas de gestão e dar maior autonomia para os gestores, além de implantar a avaliação da gestão com base no desempenho.

Champoux (2006) esclarece que a utilização do regime de competência na Nova Zelândia se iniciou pelo orçamento. Por determinação do Ato de Finanças Públicas de 1989 (PFA, em inglês), as informações orçamentárias passaram a ser geradas com base no regime de competência, o que fez com que todos os departamentos relacionados com o orçamento gerassem informações com base nesse regime. Em complemento a essa determinação, o PFA também determinou que as avaliações de desempenho financeiro fossem feitas com base em competência.

Em 1994, o Ato de Responsabilidade Fiscal (FRA, em inglês) expandiu a utilização do regime de competência para a articulação e publicação da estratégia fiscal, e, desde então, o novo regime tem sido a base tanto para o orçamento quanto para a divulgação de informações financeiras. Segundo o pesquisador, embora seja difícil precisar o verdadeiro impacto fiscal e econômico da transição, a adoção do regime de competência na Nova Zelândia foi inegavelmente de grande relevância para a gestão governamental e melhorou a disciplina fiscal na medida em que permitiu às autoridades governamentais avaliar a sustentabilidade financeira dos programas governamentais (CHAMPOUX, 2006).

Sobre a experiência do Governo da Austrália, uma das primeiras iniciativas em direção à convergência no Setor Público data de 1966, quando profissionais da contabilidade iniciaram um trabalho com o objetivo de preparar padrões normativos também para o Setor Público. Em 1984, surgiu o Accounting Standards Review Board (ASRB), com o objetivo de dar força legal às normas para o Setor Público e Privado. Em 1991, o ASRB foi renomeado para Australian Accounting Standards 
Board (AASB), com a função de definir padrões contábeis a serem seguidos na Austrália para gerar transparência e comparabilidade (AASB, 2013).

De acordo com Champoux (2006), assim como na Nova Zelândia, a transição para o regime de competência no Governo da Austrália ocorreu em um cenário de profundas mudanças econômicas, cujas reformas ocasionaram um aumento da pressão para potencializar a eficiência governamental e melhorar o desempenho fiscal.

Davis (2010) esclarece que a transição para o regime de competência no Governo da Austrália contou com o apoio de consultores que, basicamente, utilizaram as práticas contábeis por competência do Setor Privado e efetuaram as devidas adaptações para sua utilização no Setor Público, evitando o custo de desenvolver uma estrutura conceitual completamente nova. Segundo o pesquisador, com a utilização do regime de competência percebeu-se que as entidades governamentais geravam custos mais altos do que mostravam os relatórios gerados com base no regime de caixa, $\mathrm{o}$ que justificou as iniciativas de privatização e a redução do "tamanho total" do Governo.

Na experiência do Governo da Romênia, conforme relatado por Pitulice (2014), os contadores públicos consideram o regime de competência apenas como uma regra imposta, o que expõe a demanda de treinamento destes profissionais. Outra crítica apresentada pelo autor é que além de o órgão de classe dos contadores não participar da contratação dos atuantes em entidades públicas, os contadores públicos não têm obrigatoriedade de figurar como membro de órgão de classe.

Para Pitulice (2014), embora exista no Governo da Romênia um sistema de tecnologia da informação, este carece de modernização e adaptação para gerar informações através do regime de competência. Outro ponto destacado pelo pesquisador é que na Romênia a adoção do regime de competência na contabilidade pública não foi tratada como uma melhoria na gestão pública, mas, sim, como fator condicionante para aderir à União Europeia, introduzido por meio de Ordem do Ministério de Finanças, e não por leis que necessitariam de aprovação por parte do Poder Legislativo.

\subsection{Experiência Brasileira}

A transição do Governo brasileiro para o regime contábil de competência está inserida em um contexto mais amplo, denominado de processo de convergência aos padrões contábeis internacionais. Com relação ao regime contábil, a principal dificuldade tem sido suplantar a prática contábil adotada em mais de cinquenta anos de vigência da Lei $\mathrm{n}^{\circ}$ 4.320/1964, ainda em vigor, que estabeleceu em seu Art. 35 que as receitas públicas no Brasil devem ser reconhecidas apenas no momento de sua arrecadação e as despesas públicas no momento do empenho (regime de execução orçamentária e financeira).

Ao emitir orientações estratégicas para a contabilidade aplicada ao Setor Público no Brasil, o CFC apresenta que sem a adoção do regime de competência diversos ativos e passivos podem não ser reconhecidos, o que prejudicaria o objetivo de evidenciar a situação financeira e os resultados do exercício das entidades públicas. Ademais, uma preocupação adicional é resgatar o tratamento dos fenômenos do Setor Público em bases teóricas que reflitam a essência das transações governamentais e seu impacto no patrimônio, e não meramente cumprir os aspectos legais e formais (CFC, 2007).

Visando cumprir seu papel institucional, em 2008 o CFC editou um conjunto de Normas Brasileiras de Contabilidade Aplicadas ao Setor Público (NBC T SP 16), que busca a contabilidade com base no regime de competência integral (CRUVINEL e LIMA, 2011). Coube a STN, na qualidade de órgão operador do processo de convergência aos padrões contábeis internacionais, a edição do Manual de Contabilidade Aplicado ao Setor Público (MCASP), com a função de identificar instrumentos práticos para o registro das transações governamentais.

Segundo Nascimento (2014), o plano de transição do Governo brasileiro para o regime contábil de competência integral pode ser dividido em quatro fases: (i) a contabilização da execução 
orçamentária; (ii) a padronização de um plano de contas e das demonstrações contábeis nacionalmente; (iii) a definição de procedimentos contábeis específicos para as particularidades da Administração Pública brasileira; e (iv) o registro de todos os ativos, passivos, receitas e despesas pelo regime de competência.

Nascimento (2014) apresenta que entre os desafios a serem enfrentados pelo Governo brasileiro durante o processo de transição para o regime de competência estão a adaptação dos sistemas de tecnologia da informação, a capacitação e treinamento dos recursos humanos, as mudanças na cultura da Administração Pública, a superação de paradigmas, os ciclos políticos e a complexidade de alguns padrões internacionais. Apesar dos esforços que têm sido feitos no Brasil para que adoção do regime de competência passe a permear os "novos" normativos contábeis, há evidências da interferência dos ciclos políticos nesse processo (AMARAL; LIMA, 2013), como a inscrição de menos devedores na dívida ativa em anos eleitorais (CARVALHO; OLIVEIRA, 2009), o registro de despesas superavaliadas e a omissão de informações classificadas como "negativas" nas demonstrações contábeis (NASCIMENTO, 2011).

Uma crítica apresentada por Dutra e Jesus (2012) é que o processo de inovação na contabilidade pública brasileira se deu pelo desenvolvimento de normas próprias de naturezas jurídicas, administrativas e técnicas (isomorfismo normativo) e não por analogia às práticas de países desenvolvidos (isomorfismo mimético), o que dificulta a transição uma vez que é natural que o processo no Brasil incorra em erros já experimentados pelos países desenvolvidos.

\subsection{Desafios dos Governos dos Países na Transição para o Regime Contábil de Competência}

Considerando a existência de quatro regimes contábeis adotados pelos Governos dos países (PWC, 2013), a Tabela 1 relaciona os regimes adotados por cada um dos países analisados neste estudo, bem como a previsão para a adoção integral do regime de competência na contabilidade pública daqueles que ainda estão em processo de transição.

Tabela 1 - Regimes contábeis adotados pelos governos dos países analisados.

\begin{tabular}{ccc}
\hline País & Regime Adotado & Previsão para a Adoção \\
\hline Malásia (MY) & Caixa Modificado & 2019 \\
Malta (MT) & Competência Modificado & 2019 \\
Suíça (CH) & Competência & - \\
Romênia (RO) & Competência & - \\
Nova Zelândia (NZ) & Competência & - \\
Austrália (AU) & Competência & - \\
Brasil (BR) & Competência Modificado & Indefinido \\
\hline
\end{tabular}

Fonte: Os Autores.

Por meio das experiências relatadas, observa-se que o Governo da Malásia adota o regime de caixa modificado, enquanto o Governo de Malta adota o regime de competência modificado. Em ambos os países, foi definido o ano de 2019 como data limite para a transição para o regime de competência integral.

Os Governos da Suíça, da Romênia, da Nova Zelândia e da Austrália já adotam o regime contábil de competência. Segundo Dutra e Jesus (2012), o modelo normativo que regulamenta a contabilidade pública na Austrália e na Nova Zelândia em muito se assemelha às IPSAS apesar de não fazer referência a elas. No Brasil, adota-se o regime de competência modificado e, segundo Nascimento (2014), o regime de competência integral será gradualmente implantado de acordo com a maturidade da federação.

A partir dos procedimentos recomendados pelo Study 14, desenvolvido pela IFAC, e pelo Modelo de Requerimentos Básicos (BRM, em inglês), proposto pelo Ouda (2008), foram relacionados 
nove procedimentos contemplados em ambos, e analisadas a sua observância nos Governos dos países objeto de análise. Foram identificados pela letra " $\mathrm{S}$ " os países que atenderam aos procedimentos recomendados, pela letra " $\mathrm{N}$ " os países que não observaram esses procedimentos, e pela letra " $\mathrm{P}$ " os países que apenas observaram esses procedimentos parcialmente, conforme Tabela 2.

Tabela 2 - Observância aos procedimentos recomendados pelo Study 14 e pelo BRM.

\begin{tabular}{|c|c|c|c|c|c|c|c|}
\hline Procedimentos Recomendados (Study 14 e BRM) & MY & MT & $\mathbf{C H}$ & RO & NZ & AU & BR \\
\hline 1. Comprometimento Político & $\mathrm{P}$ & $\mathrm{P}$ & S & $\mathrm{N}$ & S & S & $\mathrm{P}$ \\
\hline 2. Adequação dos Recursos Humanos e Financeiros & $S$ & $\mathrm{P}$ & S & S & $S$ & S & $\mathrm{P}$ \\
\hline 3. Efetiva Estrutura de Gestão do Projeto & $\mathrm{P}$ & $\mathrm{P}$ & $S$ & $\mathrm{~N}$ & S & $S$ & $S$ \\
\hline 4. Adequação dos Sistemas Tecnológicos & $S$ & $\mathrm{~N}$ & $S$ & $S$ & $S$ & $S$ & $\mathrm{P}$ \\
\hline 5. Uso da Legislação & $S$ & $S$ & $S$ & $\mathrm{~N}$ & S & $S$ & $\mathrm{~N}$ \\
\hline 6. Estímulo & $\mathrm{N}$ & $S$ & $S$ & $S$ & S & $S$ & $S$ \\
\hline 7. Estrutura para Implantação & $\mathrm{P}$ & $\mathrm{P}$ & $S$ & $\mathrm{~N}$ & S & $S$ & $\mathrm{P}$ \\
\hline 8. Resultados & $\mathrm{N}$ & $\mathrm{N}$ & $S$ & $\mathrm{~N}$ & $S$ & $S$ & $\mathrm{~N}$ \\
\hline 9. Consequências & $\mathrm{N}$ & S & $S$ & $\mathrm{~N}$ & $S$ & $S$ & $S$ \\
\hline
\end{tabular}

Fonte: Os Autores.

Diante dos resultados apresentados na Tabela 2, observa-se que a maioria dos Governos dos países que já adotam o regime de competência observou os procedimentos recomendados pelo Study 14 e pelo BRM. Uma exceção é o Governo da Romênia que, embora utilize o regime de competência, não adota a maior parte dos procedimentos, o que talvez explique o fato de que as informações por ele geradas não serem utilizadas nem pelos gestores e nem pelas autoridades governamentais (PITULICE, 2014).

Com relação aos principais desafios observados pelos Governos dos países na transição para o regime de competência, confirmando os achados das experiências internacionais analisadas nesta Seção, o relatório da PricewaterhouseCoopers (PWC, 2013) relaciona, nesta ordem, a carência de pessoal treinado (55\%), as exigências tecnológicas (46\%), a falta de comprometimento da alta administração (27\%), o custo da conversão (27\%) e o impacto esperado sobre a situação patrimonial e financeira divulgada (18\%). Para Herbest (2010), a ausência de padrões de normas e de práticas contábeis nos Governos dos países pode mesmo estar relacionada à falta de aptidão de pessoal, o que confirma a importância da capacitação e treinamento dos servidores envolvidos nesse processo.

\section{CONSIDERAÇÕES FINAIS}

O presente estudo teve como objetivo apresentar experiências internacionais e os desafios enfrentados pelos Governos dos países na transição da contabilidade pública para o regime contábil de competência. A revisão da literatura mostrou que existem dois regimes contábeis - competência e caixa, com duas variações: regime de caixa modificado e regime de competência modificado. E que o regime de competência representa o método que reflete de forma mais aplicável o desempenho econômico no resultado do exercício, segundo o qual as receitas e as despesas são reconhecidas independentemente da entrada ou da saída de recursos financeiros na entidade.

Um destaque é dado ao fato de os relatórios financeiros das Normas Internacionais de Contabilidade Aplicadas ao Setor Público e das estatísticas financeiras governamentais levar em consideração informações financeiras geradas a partir do regime de competência. Outra constatação é que o posicionamento das grandes economias mundiais para adoção desse regime evidencia a sua importância no âmbito dos Governos dos países para alcance de objetivos propostos pela nova Administração Pública, que tem foco no resultado e busca a eficiência administrativa.

De acordo com o estudo, pesquisas têm sido desenvolvidas visando apresentar procedimentos que permitam que os Governos dos países promovam a transição dos seus regimes contábeis para o regime de competência, a exemplo do Study 14 desenvolvido pela IFAC, e do Modelo de 
Requerimentos Básicos (BRM, em inglês) proposto por Ouda (2008), com a recomendação de adoção de nove procedimentos, quais sejam: comprometimento político, adequação dos recursos humanos e financeiros, efetiva estrutura de gestão do projeto, adequação dos sistemas tecnológicos, uso da legislação, estímulo, estrutura para implantação, resultados e consequências.

Ao trazer a experiência dos Governos dos países, foram analisadas as experiências monitoradas pela IFAC nos Governos da Malásia, Malta e Suíça; as experiências relatadas na literatura (Romênia, Nova Zelândia e Austrália), coletadas de publicações acadêmicas; e a experiência vivenciada pelo Governo brasileiro, por meio de informações coletadas no sítio da Secretaria do Tesouro Nacional do Brasil e de artigos acadêmicos publicados sobre o assunto. Das experiências relatadas, verificou-se que os Governos da Suiça, Austrália e Nova Zelândia seguiu todos os procedimentos recomendados pelo Study 14 e pelo BRM, e que a adoção do regime de competência melhorou a disciplina fiscal desses países na medida em que permitiu às autoridades governamentais avaliar a sustentabilidade financeira dos programas governamentais.

Dos países que já adotam o regime de competência integral, apenas o Governo da Romênia não seguiu todos os procedimentos recomendados pelo Study 14 e pelo BRM, o que pode explicar o fato de as informações por ele geradas não serem utilizadas nem pelos gestores nem pelas autoridades governamentais locais. No caso dos Governos da Malásia e de Malta, definiram o ano de 2019 como data limite para a transição para o regime de competência integral.

No caso do Brasil, a maior dificuldade está em relacionar o regime orçamentário (estabelecido para os registros de natureza orçamentária) com o regime contábil (que deve ser a base dos registros de natureza patrimonial), resultando na adoção do regime de competência modificado, sem previsão para adoção integral do regime de competência. Quanto aos maiores desafios observados no processo de transição, destacam-se, nessa ordem, carência de pessoal treinado, exigências tecnológicas, falta de comprometimento da alta administração, custo da conversão e impacto esperado sobre a situação patrimonial e financeira divulgada.

Diante do exposto, entende-se que o presente estudo vem contribuir para a atualização da literatura no que tange ao posicionamento dos governos de economias mundiais quanto à adoção do accrual basis em sua contabilidade e, principalmente, por evidenciar os principais procedimentos observados durante o processo de transição. Para futuras pesquisas, recomenda-se que sejam monitorados os países contemplados nesse estudo que ainda estão em processo de transição, para verificar se os prazos foram cumpridos e quais consequências a adoção do novo regime trouxe para a qualidade da informação contábil prestada pelos seus Governos.

\section{REFERÊNCIAS}

AASB - AUSTRALIAN ACCOUNTING STANDARDS BOARD (2013). AASB Board. Disponível em: http://www.aasb.gov.au/AASB-Board.aspx. Acesso em: 27 ago. 2014.

AMARAL, Guilherme Fernandes; LIMA, Diana Vaz de. A contribuição da nova contabilidade pública sobre os efeitos dos ciclos políticos no Brasil. Revista Ambiente Contábil, v. 5, n. 2, p. 173-18, jul./dez. 2013.

BORGES, Thiago Bernardo; MARIO, Poueri do Carmo; CARDOSO, Ricardo Lopes; AQUINO, André Carlos Busanelli de. Desmistificação do regime contábil de competência. 2010. Revista de Administração Pública, v. 44, n. 4, p. 877-901, 2010. 
BRASIL. Lei noo . 4320, de 4 de março de 1964. Estatui normas gerais de direito financeiro para a elaboração e controle dos orçamentos e balanços da União, dos Estados, dos Municípios e do Distrito Federal. 1964.

BRASIL. Lei Complementar n⿳‥ 101, de 4 de maio de 2000. Estabelece normas públicas voltadas para a responsabilidade na gestão fiscal e dá outras providências. 2000.

CARVALHO, F. A.; OLIVEIRA, K. V. A contabilidade governamental e a teoria dos ciclos políticos: uma análise empírica fiscal e contábil sobre os municípios do estado do Rio de Janeiro - 1998/2006. Revista de Educação e Pesquisa em Contabilidade, Brasília, v. 3, n. 1, p. 46-64, 2009.

CFC - CONSELHO FEDERAL DE CONTABILIDADE. Orientações Estratégicas para Contabilidade Aplicada ao Setor Público no Brasil. 2007. Disponível em: http://cfc.org.br. Acesso em: 24 set. 2014.

CFC - CONSELHO FEDERAL DE CONTABILIDADE. Resolução CFC $n^{\circ}$. 750, de 29 de dezembro de 1993. Dispõe sobre os Princípios de Contabilidade. Disponível em: http://cfc.org.br. Acesso em: 24 set. 2014.

CFC - CONSELHO FEDERAL DE CONTABILIDADE. Resolução CFC $n^{\circ}$. 1.128, de 21 de novembro de 2008. Aprova a NBC T 16.1 - Conceituação, Objeto, e Campo de Aplicação. Disponível em: http://cfc.org.br. Acesso em: 24 set. 2014.

CFC - CONSELHO FEDERAL DE CONTABILIDADE. Resolução CFC $n^{\circ}$. 1.282, de 28 de maio de 2010. Atualiza e consolida dispositivos da Resolução n⿳o. 750/93, que dispõe sobre os Princípios de Contabilidade. Disponível em: http://cfc.org.br. Acesso em: 24 set. 2014.

CHAMPOUX, Mark. Accrual accounting in New Zealand and Australia: issues and solutions. In: Harward Law School Federal Budget Policy Seminar (Briefing Paper No. 27), April. 2006.

CHAN, James L. As NICSPS e a contabilidade governamental de países em desenvolvimento. Revista de Educação e Pesquisa em Contabilidade, v. 4, n. 1, p. 1-17, 2010.

CRUVINEL, Daniel Pereira; LIMA, Diana Vaz. Adoção do Regime de Competência no Setor Público Brasileiro Sob a Perspectiva das Normas Brasileiras e Internacionais de Contabilidade. Revista de Educação e Pesquisa em Contabilidade, v. 5, n. 3, 2011.

DAVIS, Nicholas. Accrual Accounting and the Australian Public Sector: A Legitimation Explanation. Australian Accounting, Business and Finance Journal, v. 4, n. 2, p. 61-78, 2010.

DIAMOND, Jack. Performance budgeting: is accrual accounting required? IMF Working Paper, 2002. Disponível em: http://papers.ssrn.com/sol3/papers.cfm?abstract id=880949. Acesso em: 27 ago. 2014.

DUTRA, Tiago Alves de Gouveia Lins; JESUS, Maria Antónia Jorge de. Adoção do regime de competência e convergência com as normas internacionais na contabilidade pública: um estudo comparado entre Brasil e países desenvolvidos da OCDE. XV Encuentro AECA. Esposende, 2012. Disponível em: http://www.aeca1.org/xvencuentroaeca/cd/29f.pdf. Acesso em: 17 nov. 2014. 
Ernst \& Young. Overview and comparison of public accounting and auditing practices in the 27 EU Member States. Final Report, 2012. Disponível em: http://epp.eurostat.ec.europa.eu/portal/page/portal/government finance statistics/documents/study on public accounting and auditing_2012.pdf. Acesso em: 16 out. 2014.

FEE - FÉDÉRATION DES EXPERTS COMPTABLES EUROPÉENS. Accrual accounting in the public sector. Brussels: Paper from the FEE Public Sector Committee, 2007. Disponível em: http://www.iasplus.com/en/binary/europe/0701feeaccrual.pdf. Acesso em: 27 out. 2014.

GUTHRIE, James. Application of accrual accounting in the Australian public sector-rhetoric or reality. Financial Accountability \& Management, v. 14, n. 1, p. 1-19, 1998.

HEPWORTH, Noel. Preconditions for successful implementation of accrual accounting in central government. Public Money \& Management, v. 23, n. 1, p. 37-44, 2003.

HERBEST, Fabrício Gustavo. Regime de competência no setor público: a experiência de implementação em diversos países. In: CONGRESSO ANPCONT, 4., Anais... Natal/RN, 2010.

IFAC - INTERNATIONAL FEDERATION OF ACCOUNTANTS. The Conceptual Framework for General Purpose Financial Reporting by Public Sector Entities. Final Pronouncement. USA: IFAC, 2014a.

IFAC - INTERNATIONAL FEDERATION OF ACCOUNTANTS. Handbook of International Public Sector Accounting Pronouncements. USA: IFAC, 2014b.

IFAC - INTERNATIONAL FEDERATION OF ACCOUNTANTS. Study 14: transition to the accrual basis of accounting: guidance for governments and government entities. 3. ed. USA: IFAC, 2011.

IFAC - INTERNATIONAL FEDERATION OF ACCOUNTANTS. A Closer Look At: Malaysia. USA: IFAC, 2013.

IFAC - INTERNATIONAL FEDERATION OF ACCOUNTANTS. A Closer Look At: Malta. USA: IFAC, 2014.

IFAC - INTERNATIONAL FEDERATION OF ACCOUNTANTS. A Closer Look At: Switzerland. USA: IFAC, 2014.

LÜDER, Klaus. Research in Comparative Governmental Accounting Over the Last Decade-Achievements and Problems. US: Springer, 2002.

MANGUALDE, Bruno Ramos. Perceptions of benefits and challenges of public sector accounting reforms: a cross-sectional comparison between Brazilian and English local governments. University of Birmingham, 2013.

NASCIMENTO, L. P. A efetividade dos ciclos politicos nos municípios brasileiros: uma abordagem contábil. 2011. 122 p. Dissertação (Mestrado em Contabilidade) - Universidade Federal de Santa Catarina, Florianópolis, 2011. 
NASCIMENTO, Leonardo Silveira. Public Sector Accounting and the Move to Accrual Accounting The Brazilian Experience. In: World Congress of Accountants. Rome, 2014.

NIYAMA, Jorge Katsumi. Contabilidade Internacional. São Paulo: Atlas, 2013.

OUDA, Hassan AG. Towards a Generic Model for Government Sector Reform: the New Zealand Experience. International Journal Financial Management, v. 8, n. 2, p. 91, 2008.

PITULICE, PhD Lecturer Ileana Cosmina. Accrual Accounting Adoption in The Romanian Public Sector. Revista Română de Statistică, nr, p. 67, 2013.

PWC - PRICEWATERHOUSECOOPERS. Uma nova era na contabilidade governamental. 2013. Disponível em: http://www.pwc.com.br/pt/publicacoes/setores-atividade/servico-governo-setor-publico/tl-ipsas-survey.jhtml. Acesso em: 12 nov. 2014.

RAUPP, Fabiano Maury; BEUREN, Ilse Maria. Metodologia da pesquisa aplicável ás ciências sociais: Como elaborar trabalhos Monográficos em contabilidade: teoria e prática. 3. ed. São Paulo: Atlas, 2006.

SOUSA, Rossana Guerra de; VASCONCELOS, Adriana Fernandes de; CANECA, Roberta Lira; NIYAMA, Jorge Katsumi. O Regime de Competência no Setor Público Brasileiro: uma Pesquisa Empírica sobre a Utilidade da Informação Contábil. 2013. 12f. Revista Contabilidade \& Finanças, v. 24, n. 63, p 219-230, 2013.

WILGES, Ilmo José. Finanças públicas: orçamento e direito financeiro. 2. Ed. Editora AGE Ltda, 2006. 